\title{
A Histopathological Study on the Carp Fed $\alpha$-tocopherol Deficient Diets Including Oxidized Methyl Linolate
}

\author{
Teruo MiYAZAKI \\ Faculty of Fisheries, Mie University, Edobashi, Tsu, Mie 514, Japan
}

(Received November 20, 1985)

\begin{abstract}
Five month feeding experiments were conducted on the carp, Cyprinus carpio, with diets which included oxidized methyl linolate of unsaturated fatty acid. The experimental diets included $10 \%$ of $30,40,90$ and $200 \mathrm{hrs}$-oxidized methyl linolate and 0 or $50 \mathrm{mg} \alpha$-tocopherol acetate per $100 \mathrm{~g}$ diet. The diets for control included $10 \%$ purified soy bean oil and 0 or $25 \mathrm{mg} \alpha$-tocopherol acetate per $100 \mathrm{~g}$ diet. Carps fed the tocopherol free diets including oxidized methyl linolate showed less growth and visibly thinner across the back. The histopathological signs were characterized by atrophy and necrosis of white muscle fibers and visceral ceroidosis. Carps fed a diet containing $40 \mathrm{hrs}$ oxidized methyl linolate with $50 \mathrm{mg} \alpha$-tocopherol acetate and a tocopherol free diet including soy bean oil showed lesser growth, visceral ceroidosis and no sign of myopathy. No pathological change was found in carps fed the diet including soy bean oil supplemented with $25 \mathrm{mg} \alpha$-tocopherol acetate. These results indicated nutritional myopathy of the carp was caused by oxidized fatty acid and tocopherol deficiency.
\end{abstract}

Nutritional myopathy has been found in cultured puffer, Takifugu rubripes (ENDo et al., 1979), yellowtail, Seriola quinqueradiata (KUBOTA et al., 1980), carp, Cyprinus carpio (MIYAZAKI et al., 1981 ) and rainbow trout, Salmo gairdneri (KUBOTA et al., 1981) when these cultured fishes were fed rancid feed. This disease is characterized externally by the atrophied back, and histopathologically by degeneration of muscle fibers of the lateral musculature and visceral ceroidosis. Similar signs were reported in carp (НАSHIMOTo et al., 1966; AOE et al., 1972; MiYAZAKI et al., 1981), channel catfish, Ichtalurus punctatus (MURAI et al., 1974) and rainbow trout (SMITH, 1979), fed tocopherols free diets that included oxidized fish oils. Recent1y, LOVELL et al. (1984) reported that myopathy was evoked in channel catfish fed a tocopherol free diet which contained a low level of polyunsaturated fatty acid. The results on those feeding studies indicated that oxidized fish oil and/or tocopherol-deficiency caused nutritional myopathy. In this study methyl linolate of unsaturated fatty acid was oxidized for $30-200$ hrs. Feeding studies were carried out with diets including the oxidized methyl linolate with/without $\alpha$-tocopherol acetate in order to determine how the oxidized fatty acid and tocopherol-deficiency relate to the occurrence of the nutritional myopathy. Criteria for evaluation were growth and histopathological signs.

\section{Materials and Methods}

Fish and diets Carp (Cyprinus carpio) fingerlings of approximately $1.0 \mathrm{~g}$ mean body weight were obtained form a strain at the National Research Institute of Aquaculture. Thirty fish were placed into each of the 70-liter plastic aquaria. Pumped up well water flowed continuously through the aquaria at the rate of 0.5 -liters/ minute and at a mean temperature of $20^{\circ} \mathrm{C}$. The casein basal diets (Table 1) contained $5 \mathrm{~g}$ purified soy bean oil per $100 \mathrm{~g}$ diest to supplement essential fatty acids. The following seven different oils were added at $10 \mathrm{~g}$ per $100 \mathrm{~g}$ diet; 1) soy bean oil plus $25 \mathrm{mg} \alpha$-tocopherol acetate (EIZAI Co. Ltd.), 2) soy bean oil, 3) $30 \mathrm{hrs}$ oxidized methyl linolate, 4) $40 \mathrm{hrs}$ oxildized methyl linolate, 5) $90 \mathrm{hrs}$ oxidized methyl linolate, 6) $200 \mathrm{hrs}$ oxidized methyl linolate, and 7) $40 \mathrm{hrs}$ oxidized methyl linolate plus $25 \mathrm{mg} \alpha$-tocopherol acetate (Table 2). Treatment 1 was the control. Treatment 2 was for tocopherol-deficiency. Treatments 3, 4, 5 and 6 were to examine affects of oxidized fatty 
Table 1. Composition of the feeding diets

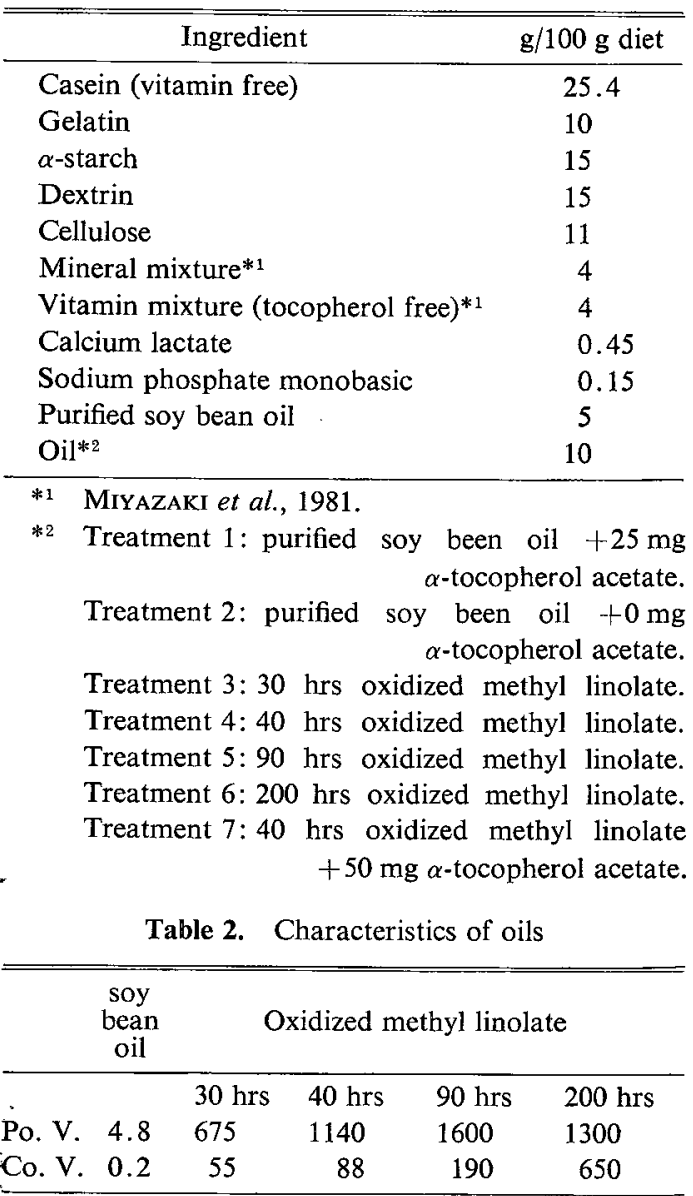

Po. V.: Peroxide value (meq $/ \mathrm{kg}$ )

Co. V.: Carbonyl value (meq $/ \mathrm{kg}$ )

acid under the condition of tocopherol-deficiency. Treatment 7 was to determine the capability of $\alpha$-tocopherol acetate to prevent pathological changes caused by oxidized fatty acid. The diets were mixed and made into pellets $2 \mathrm{~mm}$ in diameter and $2-3 \mathrm{~mm}$ in length. The pellets were dried for 3 hours at room temperature and were stored frozen at $-10^{\circ} \mathrm{C}$ until a few hours before feeding. The fish were fed daily several times to near the satiation level. The fish were weighed once a month over the 5-month experimental period.

Gross and histopathological examinations. Fish in each treatment were examined for external signs of myopathy during the experimental period. At the end of the experiment, ten fish, including sick fish, were collected from each treatment. Lateral muscle and visceral organs were fixed in $10 \%$ formalin, embedded in paraffin and sectioned (3-7 $\mu \mathrm{m}$ ) for light microscopic examination. The sections were stained with Mayer's hematoxylin and eosin (H-E), Azan, periodic acid-Schiff's (PAS) reaction, Sudan black B, aldehyde fuchsin, Berlin blue and Ziehl-Neelsen's method.

\section{Results}

Weight gain. After three months, fish fed the tocopherol free diets containing oxidized methyl linolate (treatments $3,4,5,6$ and 7) were smaller than fish on other treatments. After five months, fish in the above groups (treatments 3. 4, 5, 6 and 7) showed less weight gain and were significantly smaller than fish on other treatments $(P<0.05)$ (Table 3). There was no difference in the average size between the fish in the control and tocopheroldeficiency groups.

Tadle 3. Results on feeding examination

\begin{tabular}{ccc}
\hline & $\begin{array}{c}\text { Initial } \\
\text { mean }(\mathrm{g})\end{array}$ & $\begin{array}{c}\text { Percent gain } \\
(\%)\end{array}$ \\
\hline Treatment 1 & 1.0 & 760 \\
Treatment 2 & 1.0 & 590 \\
Treatment 3 & 1.0 & 430 \\
Treatment 4 & 1.0 & 447 \\
Treatment 5 & 1.0 & 440 \\
Treatment 6 & 1.0 & 471 \\
Treatment 7 & 1.0 & 699 \\
\hline
\end{tabular}

Gross signs. After three months, several fish in groups fed the tocopherol free diets containing 30,40 and $90 \mathrm{hrs}$ oxidized methyl linolate showed visibly thinner across the back indicating myopathy. At the end of the experiment (five months), approximately $50 \%$ of fish in the above groups showed visibly thin backs. These diseased fish had pale gills, pale livers and atrophic visceral organs. No sign of myopathy was observed among the fish groups fed $40 \mathrm{hrs}$ oxidized methyl linolate plus $50 \mathrm{mg} \alpha$-tocopherol acetate, and $200 \mathrm{hrs}$ oxidizedmethyl linolate without $\alpha$-tocopherol acetate, although all of them showed the lesser growth. The fish in the tocopherol-deficiency group had the soft body, although they showed not sign of myopathy. No external sign was found in the control fish. 
Histopathological signs. Histopathological examination was randomly done on ten fish of each group. $50-60 \%$ of fish in the groups fed tocopherol free diets including 30, 40 and $90 \mathrm{hrs}$ oxidized methyl linolate showed mild to severe myopathy of the lateral white musculature. One of ten fish in the $200 \mathrm{hrs}$ oxidized methyl linolate-fed group showed mild myopathy. These mild cases showed focally atrophy, necrosis or split of fibers in white musculature. The moderate cases showed development of muscular degeneration and necrosis. Muscle fibers showing necrosis, atrophy and split were observed throughout the white musculature (Fig. 1). Necrotized muscle fibers were invaded by macrophages showing phagocytosis. In visceral organs of the above cases, ceroid-laden macrophages increased in numbers in the liver (Fig. 2B), spleen, pancreas and kidney. Ceroid showed positive reactions to stain with Sudan black B, aldehyde fuchsin and PAS, and was acid fast with Ziehl-Neelsen's method, but negative with H-E and Berlin blue. Hepatocytes, spleen, nephrons, pancreatic acinous cells, Langerhans's islets, digestive tracts, heat, gills and brain showed no obvious pathological change.

In the severe cases, most of the white muscle fibers underwent necrosis, atrophy with separation of sarcoplasms, severe atrophy and disappearance, followed by edema and the production of connective tissues in the musculature (Fig. 3). Such a myopathy occurred symmetrically in the both sides of the lateral musculature. Spinal ganglia and nerve fibers belonging to the affected myomeres with myopathy did not show obvious pathological changes. Ceroid-laden macrophages increased the numbers in visceral organs including the liver (Fig. 2C), spleen, pancreas and kidney. Hepatic cells underwent atrophy and ceroid deposition. B-cells of Langerhans's islets were slightly degranulated (Fig. 4B). Nephrons, digestive tracts, heart, hematopoietic tissue, gills, eyes and brain showed no obvious pathological changes.

On the other hand, fish without myopathy in the above groups showed more increased numbers of ceroid-laden macrophages in visceral organs than those of the control fish.

All fish fed $40 \mathrm{hrs}$ oxidized methyl linolate plus $50 \mathrm{mg} \alpha$-tocopherol acetate showed no evidence of myopathy, but ceroidosis of visceral organs in the comparable degree to that of the fish without myopathy among fish fed 40 hrs oxidized methyl linolate without tocopherol.

Fish in the tocopherol-deficiency group displayed no evidence of myopathy, although they sowed slight ceroidosis in visceral organs.

Control fish showed no evidence of myopathy (Fig. 1A) but a few of ceroid-laden macrophages in the visceral organs (Fig. 2A).

\section{Discussion}

Nutritional myopathy syndrome is characterized by severe degeneration of the lateral musculature and visceral ceroidosis, and occurred in cultured fishes such as puffer (ENDO et al., 1979), yellowtail (KuвOTA et al., 1980) and rainbow trout (Kubota et al., 1981). According to Aoe et al. (1972), Hashimoto et al. (1966), MURAi et al. (1974) and MIYAZAKI et al. (1981), tocopherol-deficient diet's containing oxidized oils could evoke similar symptoms in carps and channel catfish. Lovell et al. (1984) revealed severe myopathy occurred in channel catfish fed $\alpha$-tocopherol-deficient diets without oxidized oil. SMITH (1979) decsribed rainbow trout fed the diet containing oxidized fish oil showed hepatocytic ceroidosis. These results on the feeding studies indicated that tocopheroldeficiencies and administration of oxidized oils caused severe degeneration of the lateral musculature and visceral ceroidosis. In the present study, methyl linolate of a fatty acid was oxidized and administered with tocopherol free diets to fingerling carps. The results on this study indicated that in the case of the carp oxidized fatty acid and tocopherol-deficiency caused myopathy. The results also indicated that simple tocopherol-deficiency did not cause myopathy for at least five months and the supplement with $50 \mathrm{mg}$ of $\alpha$-tocopherol acetate prevented the occurrence of myopathy. Methyl linolate oxidized for short periods (30, 40 and $90 \mathrm{hrs}$ ) had a stronger affect on the musculature than one oxidized for a long time $(200 \mathrm{hrs})$ did. The peroxide value of oxidized methyl linolate was decreased in $200 \mathrm{hrs}$ after $90 \mathrm{hrs}$ oxidation. These facts indicated oxidized fatty acid with the increasing peroxide values was more toxic to muscle fibers than one with a decreasing peroxide value due to the long time oxidation. 
YoKoTE (1970) reported spontaneous diabetes of carps caused severe damage of muscle fibers of the lateral musculature. But in the present study, any sign of diabetes such as degeneration of Bcells of Langerhans's islets and microangiopathy could not be found in the carps showing severe myopathy. This indicated that nutritional myopathy was caused by tocopherol-deficiency and oxidized fatty acid, and was a different disease from diabetes.

\section{Acknowledgment}

The author wish to express my thanks to Professors Dr. R. T. Lovell of Auburn University and Dr. S. S. Kubota of Nippon Veterinary and Zootechnical College for valuable suggestion, and Dr. K. Nose of Natural Research Institute of Aquaculture for analysis of oxidized methyl linolata.

\section{References}

Aoe, H., Abe, T., Saito, H., and Koyama, H. (1972): Protective effects of tocols on muscular dystrophy of young carp. Bull. Jap. Soc. Sci. Fish., 38, 845-851.

Endo, M., Miyazaki, T., Kubota, S. S., Oobayashi, M. and Matumoto, M. (1979): Studies on nutritional myopathy syndrome in cultured fishes-II. Nutritional myopathy of puffer fry. Fish Pathol. 13, 183-187.

Hashimoto, Y., OKaichi, T., Watanabe, T., FuruKAWA, A. and UMEZU, T. (1966): Muslce dystrophy of carp due to oxidized oil and the preventive effects of vitamin E. Bull. Jap. Soc. Sci. Fish., 32, 64-69.
Kubota, S. S., Funahashi, N., Endo, M. and MiyaZAKI, T. (1980): Studies on nutritional myopathy syndrome in cultured fishes-I. Nutritional myoopathy of yellowtail. Fish Pathol., 15, 75-80.

Kubota, S. S., Miyazaki, T., Tsuda, S. and Kasuya, K. (1981): Studies on nutritional myopathy syndrome in cultured fishes-IV. Nutritional mypathy accompanying exetnsive ceroidosis in rainbow trout. Bull. Fac. Fish., Mie Univ., 8, 107-115.

Lovell, R. T., MiYazaki, T. and Rasegnator, S, (1984): Requirement for $\alpha$-tocopherol by channel catfish fed diets low in polyunsaturated tryglycerides. J. Nutri., 114, 894-901.

MiYazAKI, T. and KubOta, S. S. (1981): Studies on nutritional myopathy syndrome in cultured fishesV. Sekokeosis in the carp fed on rancid pupae of the silk-worm. Bull. Fac. Fish., Mie Univ. 8, 117129.

MiYaZAKI, T. and Kubota, S. S. (1981): Studies on nutritional myopathy syndrome in cultured fishesVI. Feeding study with oils extracted from silkworm pupa and fishes on the carp-i. Vitamin $\mathrm{E}$ deficient diet based on defatted white fish meal. Bull. Fac. Fish., Mie Univ., 8, 131-147.

MuRAI, T. and ANDREWs, J. W. (1974): Interactions of dietary $\alpha$-tocopherol, oxidized menhaden oil and ethoxyquin on channel catfish (Ichtalurus punctatus). J. Nutri., 104, 1416-1431.

SMItH, C. E. (1979): The prevention of liver lipoid degeneration (ceroidosis) and microcytic anaemia in rainbow trout, Salmo gairdneri $\mathbf{R}$. fed rancid diet: a preliminary report. J. Fish. Diseas., 2, 429-437.

YoKote, M. (1970): Sekoke disease, spontaneous diabetes in carp, Cyprinus carpio, found in fish farms-I. Pathological study. Bull. Freshwater Fish. Res. Labo., 20, 39-72. 


\section{Explanation of Figures}

Fig. 1A. Cross section of white lateral musculature of control fish (25 $\mathrm{mg} \alpha$-tocopherol/100 g diet + purified soy bean oil) showing uniform size and spacing of muscle fibers. H-E, $\times 160$.

Fig. 1B. Cross section of white lateral musculature of fish fed the diet containing 90 hrs oxidized methyl linolate showing necrosis of muscle fibers. H-E, $\times 160$.

Fig. 1C. Cross section of white lateral musculature of fish fed the diet containing 30 hours oxidized methyl linolate showing atrophy (A) and split (S) of muscle fibers. H-E, $\times 160$.

Fig. 2A. Liver (L) and pancreas (P) of control fish showing very slight migration of ceroidladen macrophages (arrow). Aldehyde fuchsin, $\times 160$

Fig. 2B. Liver (L) and pancreas (P) of fish with moderate myopathy ( 90 hours oxidized methyl linolate) showing atrophy and ceroid deposition (black granules) in the hepatocytes and ceroid-laden macrophages in pancreas (arrow). Aldehyde fuchsin, $\times 160$.

Fig. 2C. Liver (L) and pancreas (P) of fish with severe myopathy (30 hrs oxidized methyl linolate) showing atrophy and ceroid deposition in the hepatocytes and ceroid-laden macrophages in pancreas (arrow). Aldehyde fuchsin, $\times 160$.

Fig. 3A. Cross section of white lateral musculature of fish ( 30 hours oxidized methyl linolate) showing severe and extensive myopathy. Azan, $\times 50$.

Fig. 3B. A detail of Fig. 3A. All muscle fibers showed atrophy with separation of sarcoplasms and necrosis with invasions of macrophages. Azan, $\times 320$.

Fig. 4A. Langerhans's islet of control fish showing good granulated B-cells. Aldehyde fuchsin, $\times 320$.

Fig. 4B. Langerhans's islet of fish with severe myopathy (shown in Fig. 3) showing slight degranulation of B-cell. Aldehyde fuchsin, $\times 320$. 


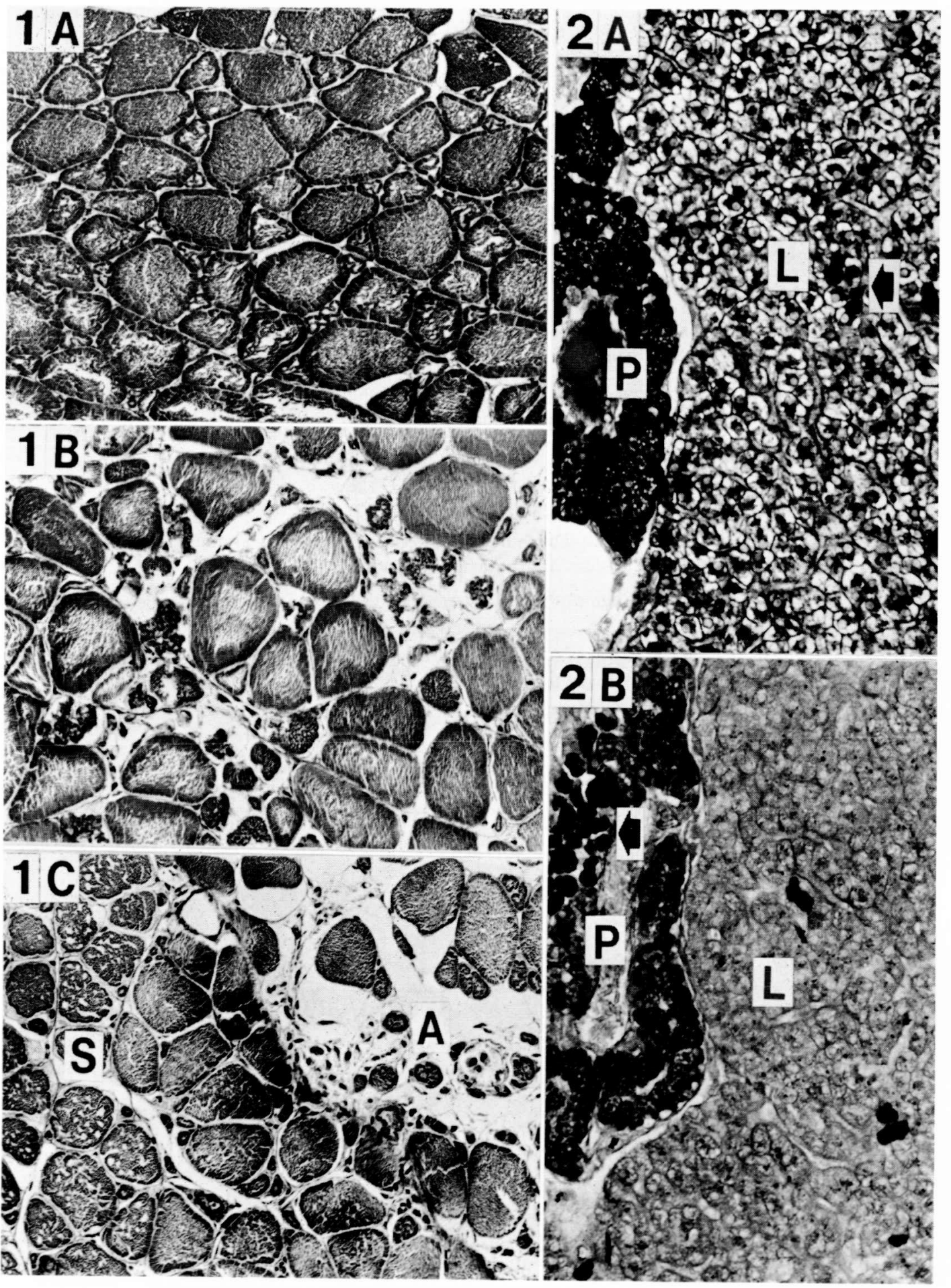




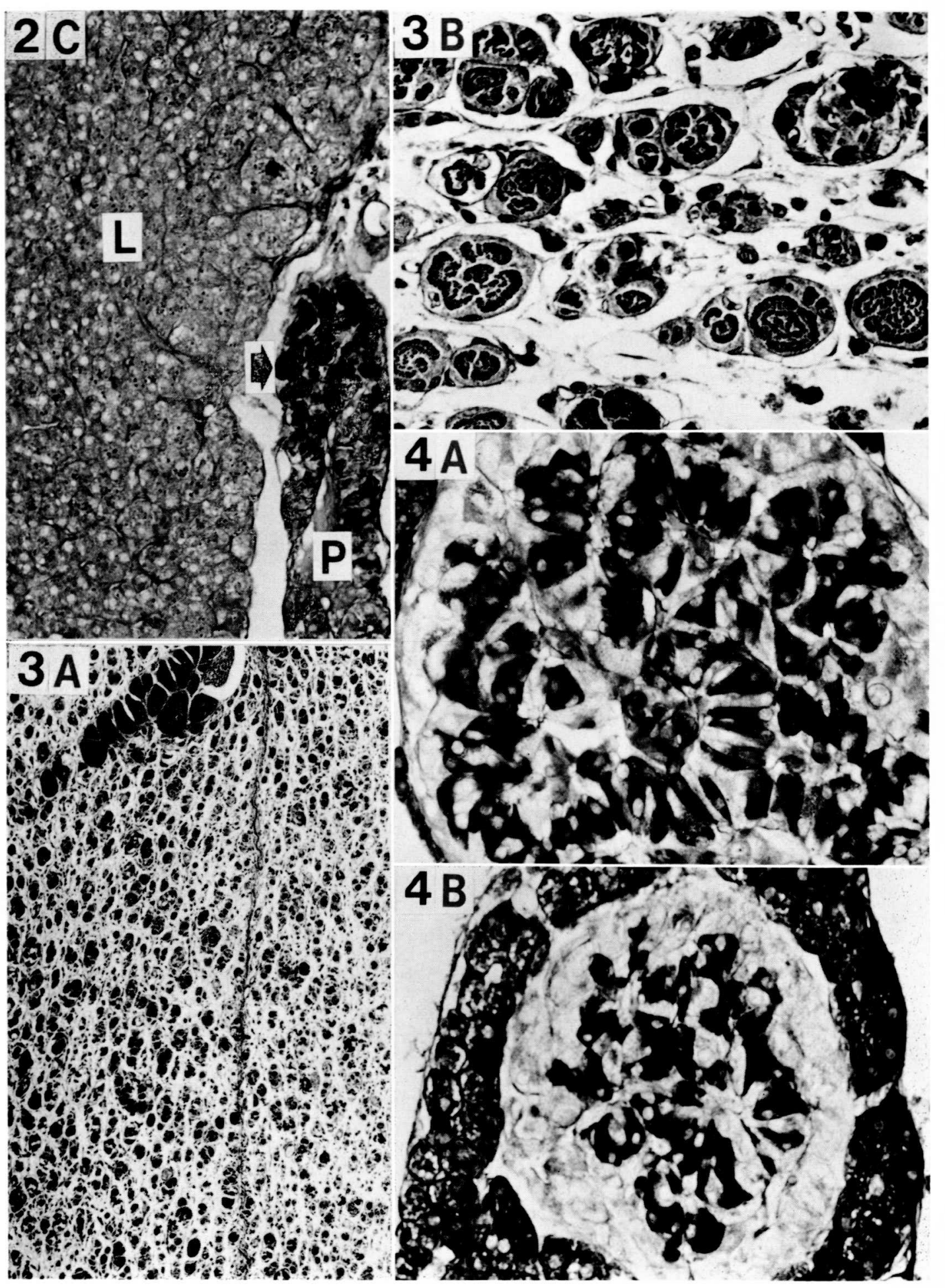

